\title{
Functionalized Multiwalled Carbon Nanotubes-Reinforced Vinylester/Epoxy Blend Based Nanocomposites: Enhanced Mechanical, Thermal, and Electrical Properties
}

\author{
Ankita Pritam Praharaj, ${ }^{1}$ Dibakar Behera, ${ }^{1}$ Tapan Kumar Bastia, ${ }^{1}$ and Arun Kumar Rout ${ }^{2}$ \\ ${ }^{1}$ School of Applied Sciences (Chemistry), KIIT University, Bhubaneswar, Odisha 751024, India \\ ${ }^{2}$ School of Mechanical Engineering, KIIT University, Bhubaneswar, Odisha 751024, India \\ Correspondence should be addressed to Ankita Pritam Praharaj; ankita.praharaj017@gmail.com
}

Received 24 July 2015; Accepted 6 September 2015

Academic Editor: Carlos R. Cabrera

Copyright (c) 2015 Ankita Pritam Praharaj et al. This is an open access article distributed under the Creative Commons Attribution License, which permits unrestricted use, distribution, and reproduction in any medium, provided the original work is properly cited.

\begin{abstract}
This paper presents a study on the mechanical, thermal, and electrical characterization of a new class of low cost multiphase nanocomposites consisting of Vinylester resin/epoxy (VER/EP) blend $(40: 60 \mathrm{w} / \mathrm{w})$ reinforced with amine functionalized multiwalled carbon nanotubes (f-MWCNTs). Five different sets of VER/EP nanocomposites are fabricated with addition of 0,1 , 3,5 , and 7 wt.\% of f-MWCNTs. A detailed investigation of mechanical properties like tensile strength, impact strength, Young's modulus, and hardness, thermal properties like thermogravimetric analysis (TGA) and thermal conductivity, electrical properties like dielectric strength, dielectric constant, and electrical conductivity, and corrosive and swelling properties of the nanocomposites has been carried out. Here, we report significant improvement in all the above properties of the fabricated nanocomposites with nanofiller (f-MWCNTs) addition compared to the virgin blend ( $0 \mathrm{wt}$. nanofiller loading). The properties are best observed in case of 5 wt.\% nanofiller loading with gradual deterioration thereafter which may be due to the nucleating tendency of the nanofiller particles. Thus the above nanocomposites could be a preferable candidate for a wide range of structural, thermal, electrical, and solvent based applications.
\end{abstract}

\section{Introduction}

Nowadays, there is an increasing interest in the use of hybrid thermosetting resins for composite applications. This interest is fueled by the potential of property improvements, for example, stiffness, strength, toughness, fiber to matrix adhesion, and hydrolytic and chemical resistance that can be achieved via a combination of thermoset resins that often show an interpenetrating network (IPN) structure [1]. The traditional way of optimizing the properties of thermosets using various fiber reinforcements can be replaced by simply blending two thermosets which represent an entirely different strategy for property enhancement due to their IPN structure. Among various polymer blends, VER/EP matrix combinations are an attractive route to promote the performance of the overall matrix combination and to overcome the inferior properties of both the components [2]. Epoxy is a versatile and widely accepted matrix material used for the fabrication of advanced composites, hardware components, electrical circuit board materials, missile equipment, coatings, adhesives, moulding compounds, and polymer composites because of its excellent bonding, thermal, mechanical, dielectric, and aging characteristics, superior thermomechanical properties, and excellent processability. However, its use is often limited because of low toughness property [3]. On the other hand, Vinylester, that is, bisphenol-A-glycidyldimethacrylate (BisGMA), has been referred to as a technologically important resin due to its high modulus and strength, high glass transition temperatures, high thermal stability, and moisture resistance. The cured BisGMA resins form a highly crosslinked three-dimensional interconnected network whose microstructure provides good engineering properties [4]. But its high viscosity results in poor handling and processability limitations. Therefore, the blending technique of both VER 

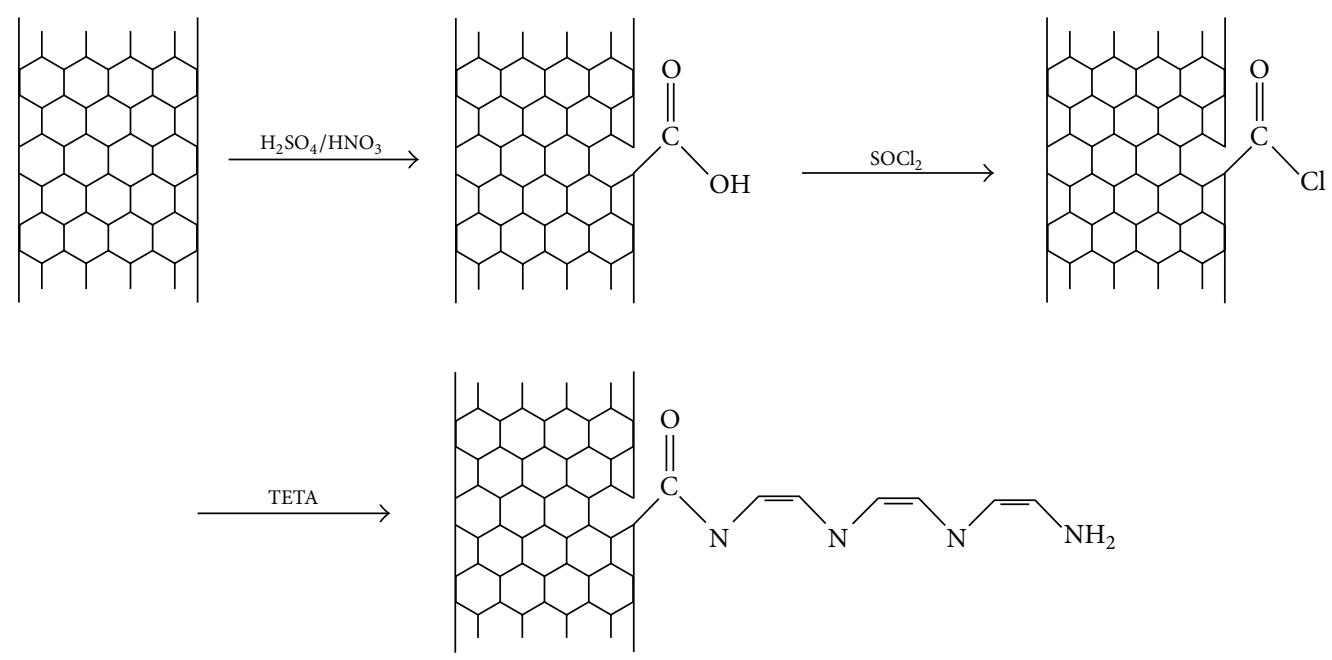

FIgURE 1: Preparation of amine functionalized MWCNTs.

and EP may be used effectively to overcome the inferior properties of both the components. Miscible polymer blends produce a newly improved material from less superior individual components. Again, because of the enhancement of the properties, such as the mechanical, thermal, and barrier properties, even at low concentrations, the nanocomposites of such blends have drawn much attention [5-9].

The primary goal of this research is to develop the VER/ EP blend $(40: 60 \mathrm{w} / \mathrm{w})$ based nanocomposites using $\mathrm{f}$ MWCNTs as reinforcement/nanofiller in different weight ratios such as $0,1,3,5$, and $7 \mathrm{wt} . \%$ and then to characterize thereof. The authors have also focused on the mechanical, thermal, electrical, corrosive, and swelling properties of the fabricated nanocomposites which have been studied in relation to the f-MWCNTs content. The results indicate improved mechanical, thermal, electrical, corrosive, and swelling properties in the reinforced nanocomposites compared to the neat blend ( $0 \mathrm{wt} . \%)$ with optimum properties exhibited by the nanocomposite with $5 \mathrm{wt} . \%$ nanofiller loading. This part of the research aims to develop low cost and high strength hybrid nanocomposites which can be specifically used for structural, thermal, electrical, and solvent based applications.

\section{Experimental Details}

2.1. Materials. MWCNTs of $>98 \%$ carbon basis and diameter and length between 5-20 nm and 1-10 $\mu \mathrm{m}(\mathrm{O} . \mathrm{D} \times \mathrm{I} . \mathrm{D} \times$ Length $=10-30 \mathrm{~nm} \times 3-10 \mathrm{~nm} \times 1-10 \mu \mathrm{m})$ prepared by chemical vapor deposition (CVD) method and dicumyl peroxide (DCP) were supplied by Sigma-Aldrich, USA. BisGMA prepolymer was synthesized by using a reported method in our laboratory [10].

\subsection{Methods}

2.2.1. Amine Functionalization of MWCNTs. Initially, carboxyl groups $(-\mathrm{COOH})$ were developed onto the surfaces of the tubes by treating with a mixture of $1: 1(\mathrm{v} / \mathrm{v})$ of
$\mathrm{H}_{2} \mathrm{SO}_{4} / \mathrm{HNO}_{3}$. For this, $0.5 \mathrm{~g}$ of MWCNTs was treated with $50 \mathrm{~mL}$ of acid mixture and refluxed in an ultrasonic bath at $55^{\circ} \mathrm{C}$ and at a frequency of $40 \mathrm{kHz}$ for $9 \mathrm{hrs}$. The mixture was then centrifuged and filtered in vacuum through a polytetrafluoroethylene membrane with a $0.45 \mu \mathrm{m}$ pore size. $10 \mathrm{~mL}$ of a water/acetone $1: 1(\mathrm{v} / \mathrm{v})$ solution was used to neutralize the mixture. The solid product was dried in an oven at $100^{\circ} \mathrm{C}$ for $9 \mathrm{hrs}$.

The amine functionalization involved the addition of $120 \mathrm{~mL}$ of freshly distilled thionyl chloride $\left(\mathrm{SOCl}_{2}\right)$ to $300 \mathrm{mg}$ of oxidized MWCNTs, heating the mixture at $70^{\circ} \mathrm{C}$ and refluxing for $24 \mathrm{hrs}$ followed by the extraction of $\mathrm{SOCl}_{2}$ by distillation and addition of $120 \mathrm{~mL}$ of TETA to the same recipient. The above mixture was then refluxed at $120^{\circ} \mathrm{C}$ for $96 \mathrm{hrs}$ and cooled to room temperature and then later centrifuged and dispersed in a beaker containing $300 \mathrm{~mL}$ of anhydrous ethanol to remove the TETA adsorbed on the tube walls. The remaining solution was filtered under vacuum and extensively washed with anhydrous ethanol. The final product was dried in an oven at $100^{\circ} \mathrm{C}$ for $12 \mathrm{hrs}$ and designated as amine functionalized MWCNTs (f-MWCNTs). The reaction scheme is shown in Figure 1.

2.2.2. VER/EP Blended Nanocomposite Fabrication. Initially, VER/EP $(40: 60 \mathrm{w} / \mathrm{w})$ were mixed together and stirred at $40^{\circ} \mathrm{C}$ for 30 mins using a mechanical stirrer. The f-MWCNTs were then added in different weight ratios, $0,1,3,5$, and $7 \mathrm{wt} . \%$, to the VER/EP blend and mixed thoroughly with mechanical stirrer for about $1 \mathrm{hr}$ and high intensity ultrasonicator for $1.5 \mathrm{hrs}$ at ambient temperature conditions. External cooling system was employed by submerging the beaker containing the mixture in an ice bath to avoid temperature rise during the sonication process, followed by stirring overnight to obtain a homogeneous and stable suspension. Then $0.05 \mathrm{~g}$ of benzoyl peroxide and hardener/catalyst/promoter $(100: 10 / 2 / 2)$ parts by weight were added to the reinforced VER/EP blend followed by stirring for 30 mins. At the beginning of fabrication, gelcoat was uniformly brushed into the 
mould and the nanocomposite mixture was poured into it. Brush and roller were used to impregnate the nanocomposite. Then the closed mould was subjected to hot press ( 5 tons) with temperature of $110^{\circ} \mathrm{C}$ for 2 hours and $160^{\circ} \mathrm{C}$ and then test specimens of required sizes were cut out from the sample sheet.

\subsection{Instruments and Measurements}

2.3.1. Fourier Transform Infrared (FTIR) Spectroscopy. FTIR spectra were collected using Thermo Nicolet Model 400 instrument equipped with a controlled temperature cell (Model HT-32 heated demountable cell used with an Omega 9000-A temperature controller).

2.3.2. Scanning Electron Microscopy (SEM). SEM was utilized to qualitatively examine the microstructure of raw MWCNTs, f-MWCNTs, and the reinforced nanocomposites. The samples were gold coated and examined using a Philips 420T scanning electron microscope with a secondary electron detector, operating at $60 \mathrm{kV}$ in the SEM mode.

2.3.3. Mechanical Testing. Young's modulus and tensile strength were evaluated using an INSTRON universal testing machine (Model 3369) according to ASTM D790-03 standard. Impact strength (IZOD) was measured in an impact tester as per D256-05. Hardness was measured under ASTMD2240 standard using durometer (hardness Shore A). Standardized hardness-measuring equipment using a sharp needle was applied directly onto the surface of specimens to measure hardness. Data reported in this work are calculated as averages of the measurement carried out for five specimens.

2.3.4. Thermal Properties Measurement. Thermogravimetric analysis (TGA) was performed on a Perkin-Elmer Series 7 thermal analyzer with an air purge in a dry nitrogen atmosphere at a heating rate of $10^{\circ} \mathrm{C} / \mathrm{min}$. The weight loss of the sample was measured as a function of temperature. Thermal conductivity was measured using Thermal Conductivity Instrument (TCI), 2022 SX211, as per ASTM E 1530 standard under $10^{-5}$ torr vacuum environment with measurement accuracy of $\pm 3 \%$. The $50 \mathrm{~mm}$ diameter and $10 \mathrm{~mm}$ thick specimens were used for this study. To ensure good contact between the test samples and the flex meter, the surface finish of the sample was improved by working with a fine emery paper.

2.3.5. Electrical Properties Measurement. Dielectric strength was tested as per IEC-60243-1 (ASTM D 149) standard at $250 \mathrm{~V}$ and $50 \mathrm{~Hz}$. Dielectric constant measurements were carried out by using Weis-500 electrochemical work station (impedance analyser) in the frequency of $1 \mathrm{MHz}$ at room temperature. Volume and surface resistance of the samples were measured according to ASTM D257 using Keithley 6517A model 8009 Resistivity Test Fixture. The specimens were copper plated for better contact after subjecting to humidity conditioning at $95 \% \mathrm{RH}$ and $37^{\circ} \mathrm{C}$.
The corresponding resistivity is calculated using the following formulas:

$$
\begin{aligned}
\sigma_{\mathrm{v}} & =\left(\frac{22.9}{t}\right) R \\
\rho_{\mathrm{s}} & =53.4 R,
\end{aligned}
$$

where $\sigma_{\mathrm{v}}$ and $\rho_{\mathrm{s}}$ are the volume and surface resistivities, respectively, $R$ is the corresponding resistance in ohms, and 22.9 and 53.4 are constants for the apparatus. The volume and surface conductivities are calculated from the resistivity values obtained from the preceding equations.

2.3.6. Corrosion Testing. For corrosion tests, five specimens $\left(12 \times 10 \times 3 \mathrm{~mm}^{3}\right.$ and exposed area of $\left.372 \mathrm{~mm}^{2}\right)$ were tested according to ASTM B117 standard. The edges of the samples were sealed with BisGMA resin and their initial weights were taken in dry condition in an electronic balance of accuracy $0.00001 \mathrm{mg}$ and model AY220. The test was then conducted by dipping the specimens in circulating salt water with $10 \mathrm{wt} . \% \mathrm{NaCl}$ concentration and $\mathrm{pH}$ value of 6.5 at a temperature of $42^{\circ} \mathrm{C}$. After a gap of 24,48 , and $72 \mathrm{hrs}$ of testing, each time the specimens were rinsed, cleaned in deionized water, and dried in an oven for $12 \mathrm{hrs}$ and final weights were taken.

2.3.7. Swelling Experiments. Swelling measurements were carried out in water, dichloroethylene $\left(\mathrm{CH}_{2} \mathrm{Cl}_{2}\right)$, and methyl ethyl ketone (MEK) at room temperature. The samples of nanocomposites were small blocks $(3 \times 3 \times 5 \mathrm{~mm})$ which were immersed in each liquid for more than two weeks. The swelling equilibrium was determined when the weights of the swollen specimens were constant. The specimens were first weighed in the swollen state. Then the swollen specimens were washed with fresh solvent and dried under vacuum at $150^{\circ} \mathrm{C}$ for three days until constant weight. The swelling index was defined as follows:

$$
\begin{aligned}
& \text { Swelling Index } \\
& =\frac{\text { volume of specimen in swollen state }}{\text { volume of specimen in dry state }} \\
& =1+\left[\frac{\left(W_{\mathrm{sw}}-W_{\mathrm{d}}\right) \times \rho_{\mathrm{sp}}}{W_{\mathrm{d}} \times \rho_{\mathrm{s}}}\right],
\end{aligned}
$$

where $W_{\mathrm{sw}}$ is weight of specimen in the swollen state, $W_{\mathrm{d}}$ is weight of specimen in dry state, $\rho_{\mathrm{s}}$ is density of solvent, and $\rho_{\text {sp }}$ is density of the specimen.

\section{Results and Discussion}

3.1. Amine Functionalization of MWCNTs. Figure 2 illustrates the FTIR spectrum of f-MWCNTs which depicts a strong and broad peak at $1631 \mathrm{~cm}^{-1}$ with a shoulder at $1707 \mathrm{~cm}^{-1}$ due to $\mathrm{C}=\mathrm{O}$ stretching vibration caused by the formation of amide linkage. The strong peaks at $2918,2850 \mathrm{~cm}^{-1}$, and $2954 \mathrm{~cm}^{-1}$ are ascribed to $-\mathrm{CH}$ stretching of the alkyl 


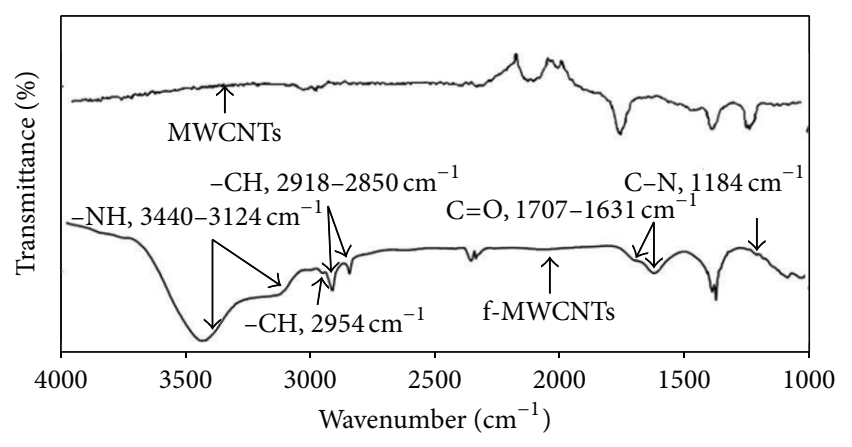

FIGURE 2: FTIR spectra of raw MWCNTs and f-MWCNTs.

chain of TETA. The peak at $1184 \mathrm{~cm}^{-1}$ corresponds to C-N stretching of amide group and the strong peaks at 3440 and $3124 \mathrm{~cm}^{-1}$ correspond to $-\mathrm{NH}$ stretching of the amine group.

The SEM micrographs of raw MWCNTs and f-MWCNTs are shown in Figures 3(a) and 3(b). The SEM of raw MWCNTs shows a regular morphology which after amine functionalization becomes quite irregular. This is expected to result in a very strong matrix-CNT interaction. The grafting of amine groups on MWCNTs does not only improve its contact with the blended matrix, but these f-MWCNTs also enhance the interfacial bonding between VER and EP.

3.2. VER/EP Blended Nanocomposites. The FTIR spectrum of the VER/EP blend ( $40: 60 \mathrm{w} / \mathrm{w})$ shown in Figure 4 represents the peaks of both VER and EP. The wide band at $3447.14 \mathrm{~cm}^{-1}$ is due to the presence of hydroxyl group. The peak at $2963 \mathrm{~cm}^{-1}$ is due to the $\mathrm{C}-\mathrm{H}$ stretching of the aromatic ring. The peaks at $2920.43 \mathrm{~cm}^{-1}$ and $2855.71 \mathrm{~cm}^{-1}$ are attributed to the $\mathrm{C}-\mathrm{H}$ stretching of aromatic ring and methyl groups, respectively. The ester carbonyl stretching is observed at $1737.14 \mathrm{~cm}^{-1}$, whereas the carbon-carbon double bond $(\mathrm{C}=\mathrm{C})$ stretching is at $1627.83 \mathrm{~cm}^{-1}$. The ring stretching vibrations of the aromatic nuclei are seen at 1463.20 and $1377.14 \mathrm{~cm}^{-1}$, respectively. The peaks at $1242.12,1165$, and $1113.11 \mathrm{~cm}^{-1}$ are due to the $\mathrm{C}-\mathrm{O}$ stretching. The oxirane peak in epoxy is observed at $910.11 \mathrm{~cm}^{-1}$. The $\mathrm{C}-\mathrm{H}$ out of plane bending vibrations are observed at 817.11 and $749.10 \mathrm{~cm}^{-1}$. All the above peaks of both VER and EP supported the formation of VER/EP blend.

Figure 5 depicts the SEM micrographs of the VER/EP blended nanocomposites filled with different compositions of f-MWCNTs $(0,1,3,5$, and 7 wt.\%). The neat VER/EP blend does not show any f-MWCNTs. The nanocomposite with 1 wt.\% f-MWCNTs exhibits less nanofillers dispersed in the matrix. $5 \mathrm{wt} . \%$ nanocomposite depicts the homogenous dispersion of $\mathrm{f}-\mathrm{MWCNT}$ as individual tubes in the matrix resulting in smooth and regular morphology. $7 \mathrm{wt} . \%$ of nanofiller concentration (Figure 5(d)) results in large amount of clustered f-MWCNTs because of the strong van der Waals resulting in poor dispersion of nanotubes in the matrix [11] which contribute to the formation of cracks (Figure 5(e)) on the surface of the nanocomposites. This may lead to reduction in the properties of the blend based nanocomposites.

\subsection{Mechanical Properties of the Nanocomposites}

3.3.1. Young's Modulus and Tensile Strength. The values of mechanical properties have been presented in relation to the varying content of f-MWCNTs in the nanocomposites. Figures 6 and 7 suggest marked improvement in the values of Young's modulus and tensile strength with the addition of f-MWCNTs into the VER/EP blend matrix. The f-MWCNTs acting as the reinforcement withstand maximum part of the load enabling efficient interfacial stress transfer. As a consequence, the strength of nanocomposites increases.

However, the increasing trend is marked up to $5 \mathrm{wt} . \%$ of f-MWCNTs loading beyond which the properties deteriorate. At higher content (7 wt.\%), the f-MWCNTs are unable to disperse adequately in the matrix because of their huge surface energy and agglomerate to form a big cluster. This leads to inhomogeneous dispersion in the polymer matrix that causes a decrease in the values of Young's modulus and tensile strength [11].

3.3.2. Impact Strength and Hardness. The effect of f-MWCNTs loading on the impact strength and hardness of VER/EP blend based nanocomposites is given in Figures 8 and 9 . The results suggested an increase in the properties with the incorporation of nanofiller into the blend matrix attaining maxima at $5 \mathrm{wt}$.\% of nanofiller.

The qualitative dispersion of nanofiller in the blend matrix and filler-matrix interaction may be the two main reasons or factors responsible for the observed trend. But the decrease in the values at $7 \mathrm{wt}$.\% may be attributed to the increased brittleness and crystallinity in the nanocomposites which restricts the movement of polymer chains. This causes microcracks when impact occurs, causing easy crack propagation. Therefore, the higher agglomeration of f-MWCNTs can cause the mechanical properties of the composites to deteriorate [12].

\subsection{Thermal Properties}

3.4.1. TGA Analysis. Figure 10 presents the curves of VER/EP blend and the nanocomposites corresponding to the mass loss as a function of temperature. The thermogram shows only one stage of decomposition for the VER/EP blend and the nanocomposites at temperatures between $340^{\circ} \mathrm{C}$ and $460^{\circ} \mathrm{C}$.

For the f-MWCNTs reinforced nanocomposites, the decomposition occurs at slightly higher temperature compared to the neat blend. The incorporation of f-MWCNTs into the VER/EP blend matrix further adds to the stability of the nanocomposites by filling in the areas of cracks and voids resulting in a tightly packed structure resistant to thermal degradation. But in case of $7 \mathrm{wt} \%$ nanocomposite, the degradation temperature seems to deteriorate due to the poor surface characteristics resulting in thermal instability.

3.4.2. Thermal Conductivity. The thermal conductivity data of the reinforced nanocomposites are shown in Figure 11. The conductivity values of all the nanocomposites increase compared to the neat blend due to the presence of $\mathrm{f}-\mathrm{MWCNTs}$. 

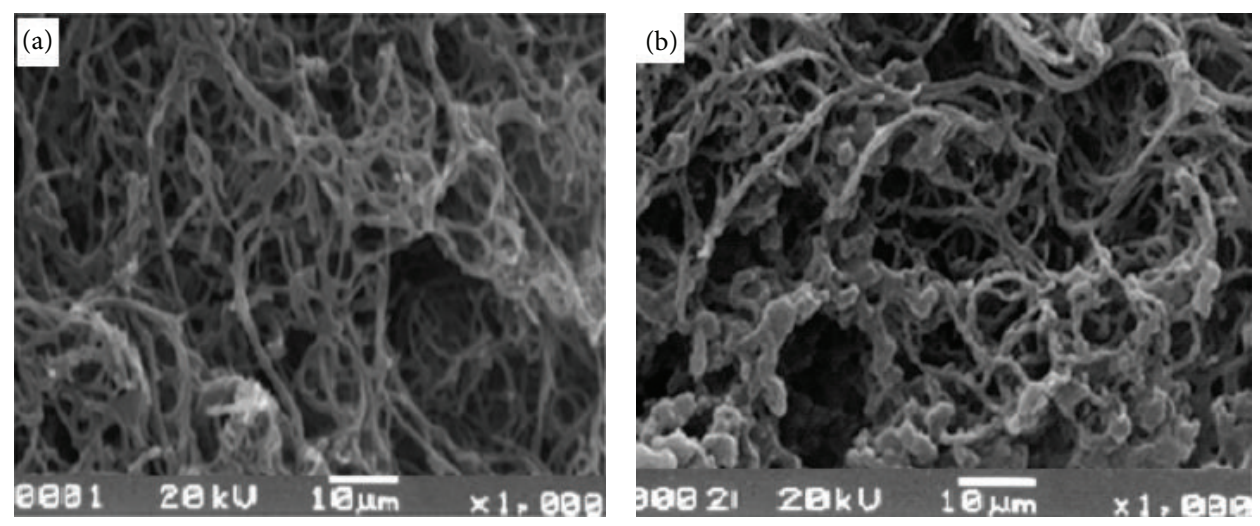

FIgURE 3: SEM of (a) raw MWCNTs and (b) f-MWCNTs.

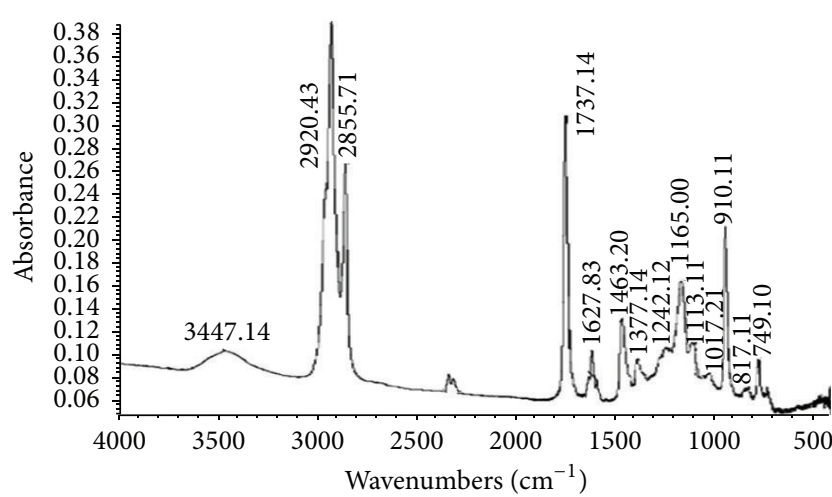

FIGURE 4: FTIR spectrum of VER/EP blend $(40: 60 \mathrm{w} / \mathrm{w})$.

But the values decrease after 5 wt. $\%$ of nanofiller content predicting it to be the best filling composition for the nanocomposites. At higher concentration (7 wt.\%), the agglomerating tendency of the nanofillers results in decreased thermal conductivity.

\subsection{Electrical Properties}

3.5.1. Dielectric Strength. The dielectric strength of the neat blend and blend based nanocomposites reinforced with varying content of $\mathrm{f}-\mathrm{MWCNTs}$ was examined and the results are illustrated in Figure 12. The nanocomposites exhibited increased dielectric strength with the nanofiller loading. 5 wt. $\%$ of $\mathrm{f}-\mathrm{MWCNT}$ content brought about $71.33 \%$ increase in dielectric strength of the nanocomposite compared to that of neat blend (VER/EP). The increase in the values may be due to the total surface area available from the nanofiller as well as its continuity. Increase in the bond strength between the blended matrix and the nanofiller [13] can also be accounted for the improved values. However, further addition of f-MWCNTs onto the blend system causes a decrease in dielectric strength due to the lower interspacing between the nanofiller particles.

3.5.2. Dielectric Constant. Polymer based nanocomposites with high dielectric constant have attracted great attention for their important technological applications such as electronic packaging and components, electromechanical devices, high performance capacitor, and electric energy storage devices. Figure 13 shows the dielectric constant of nanocomposites with increasing f-MWCNTs content at frequency of $1 \mathrm{MHz}$. The values of dielectric constant of nanocomposites are found to increase with increasing content of $\mathrm{f}-\mathrm{MWCNT}$ due to their high aspect ratio [14]. The surface modification of MWCNTs with amine also causes effective nanofiller-matrix interactions, that is, VER/EP and f-MWCNTs, giving rise to a homogeneous phase system with increased dielectric constant.

3.5.3. Electrical Conductivity. In Figure 14, the electrical conductivity results are plotted as a function of the nanofiller concentration. It was observed that there was significant improvement in the values of electrical conductivity upon nanofiller loading. A high aspect ratio (100) and high conductivity $\left[10^{4} \mathrm{~S} / \mathrm{cm}\right]$ of $\mathrm{f}-\mathrm{MWCNTs}$ enable them to make a better reinforcing effect in VER/EP blend matrix. The nanocomposites are able to exhibit increased conductivity due to the conductive effect of f-MWCNTs. It was observed that, at higher loading ( $7 \mathrm{wt} . \%)$, the filler particles tend to come closer to each other, thereby increasing the aggregation at matrix-filler interface which creates a barrier for the conduction of electric current [14].

3.6. Corrosive Properties. The corrosive tendencies of the nanocomposites are shown in Figure 15. Here, increased hours of $\mathrm{NaCl}$ treatment resulted in weight gain (oxidation) in all the composites but to a negligible extent. The uniform dispersion of the nanofiller (f-MWCNTs) in the blend matrix is facilitated by the strong interfacial interactions which ultimately reduces the formation of any type of voids on the nanocomposite surface [12]. As a result diffusion of salt water inside the matrix is reduced and thus least weight change is observed at $5 \mathrm{wt}$.\% of f-MWCNTs content. 7 wt. $\%$ of filler loading results in particle agglomeration [11], thereby forming micro voids in the matrix which helps in the easy diffusion of salt water into the nanocomposite structure showing increase in weight gain [15].

3.7. Swelling Properties. The nanocomposites were subjected to swelling to ascertain their utility in various solvent based 

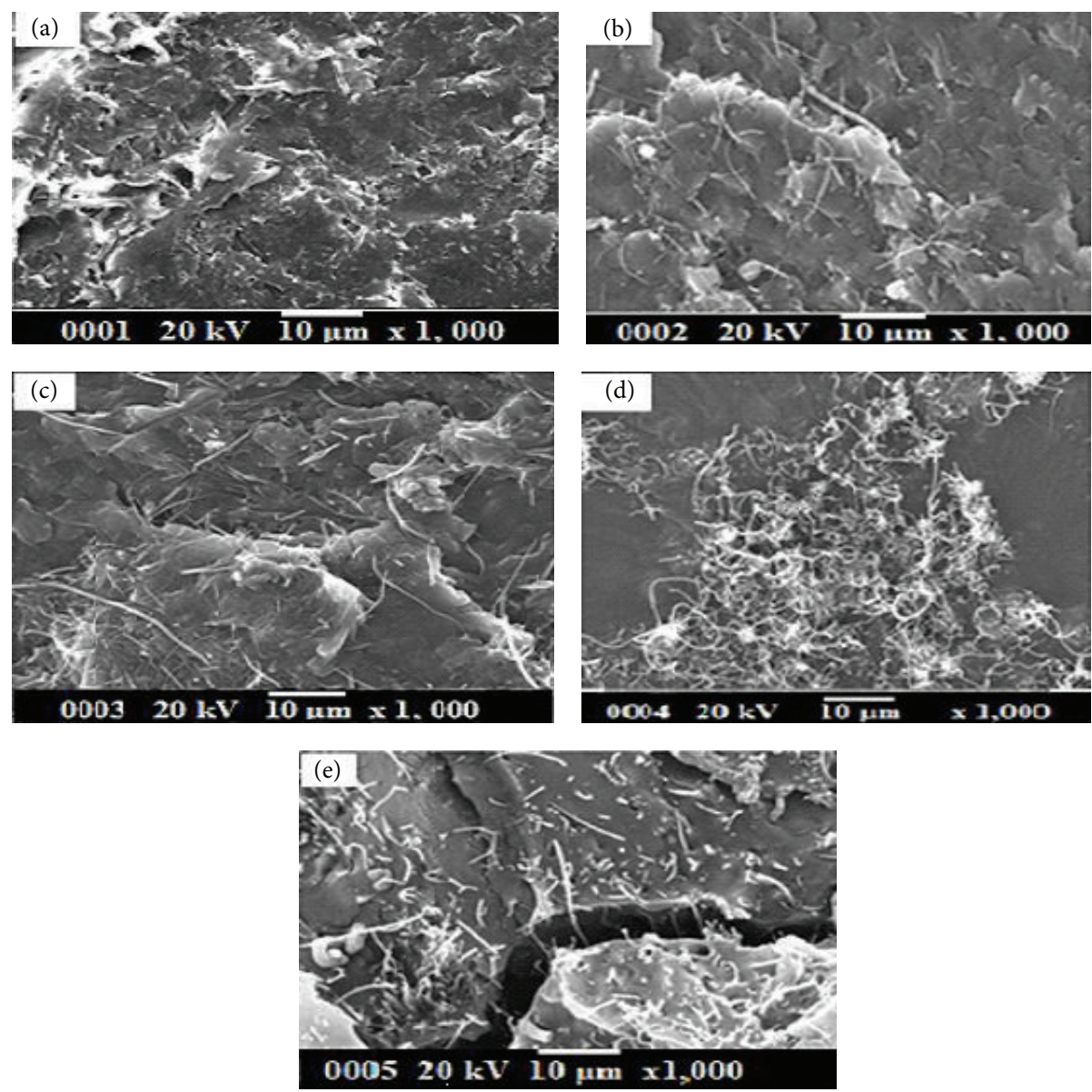

Figure 5: SEM of (a) 0 wt.\%, (b) 1 wt.\%, (c) 5 wt.\%, (d) and (e) 7 wt.\% nanocomposites.

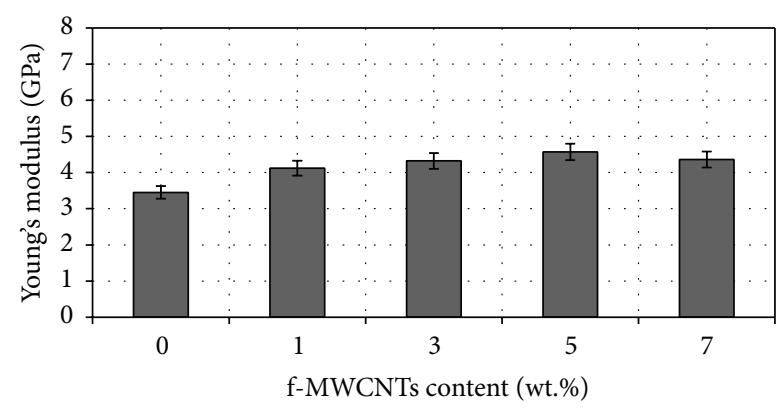

FIGURE 6: Effect of f-MWCNTs on Young's modulus of nanocomposites.

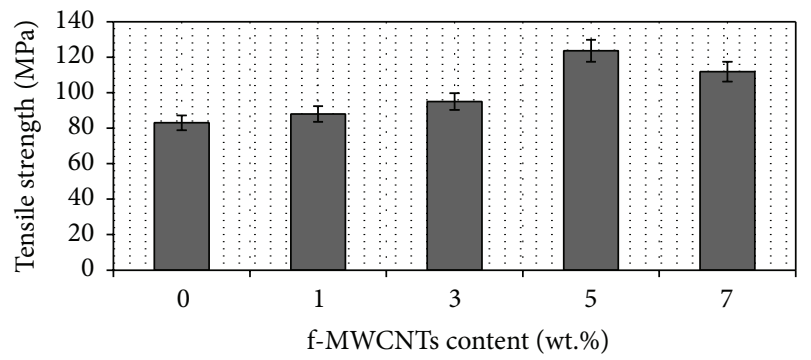

FIGURE 7: Effect of f-MWCNTs on tensile strength of nanocomposites.

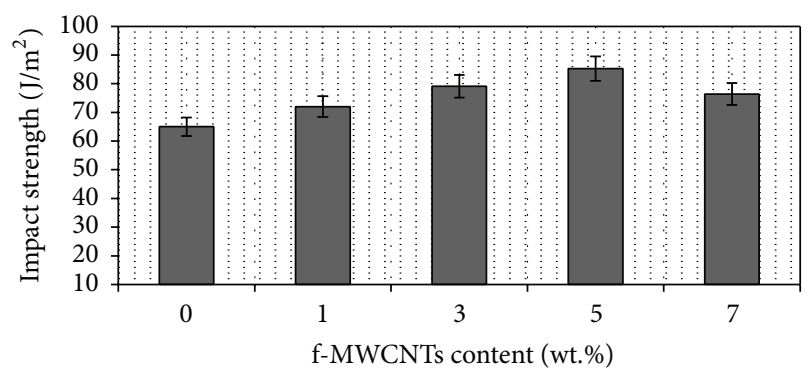

FIGURE 8: Effect of f-MWCNTs on impact strength of nanocomposites.

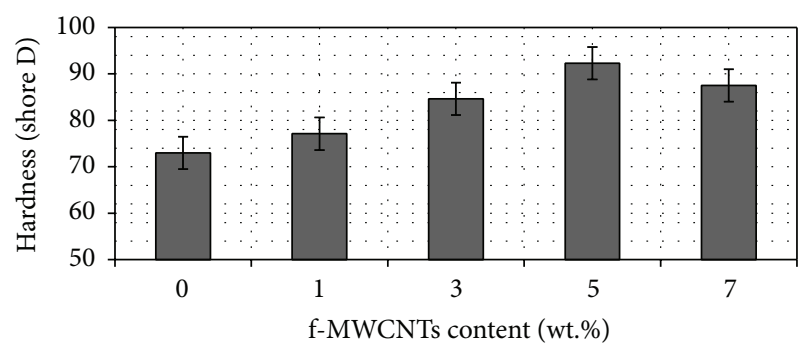

FIgURE 9: Effect of f-MWCNTs on hardness of nanocomposites. 


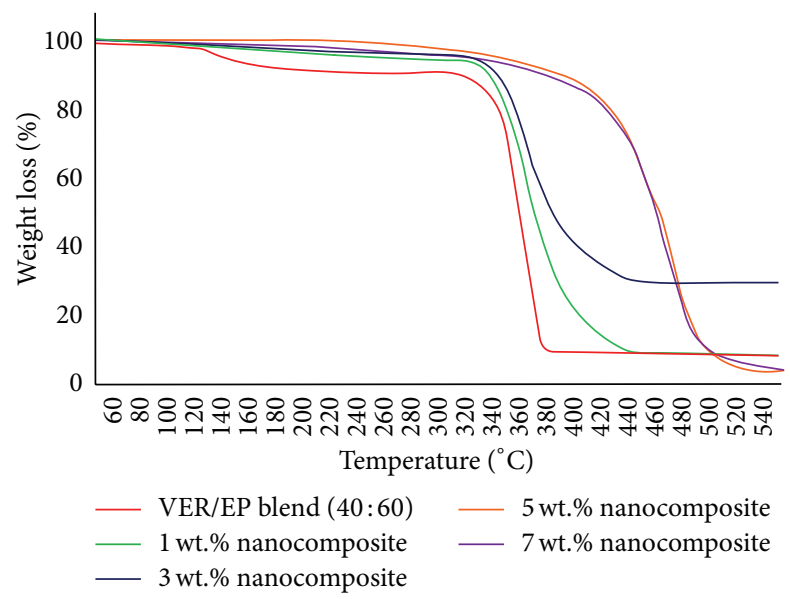

FIGURE 10: TGA analysis of nanocomposites.

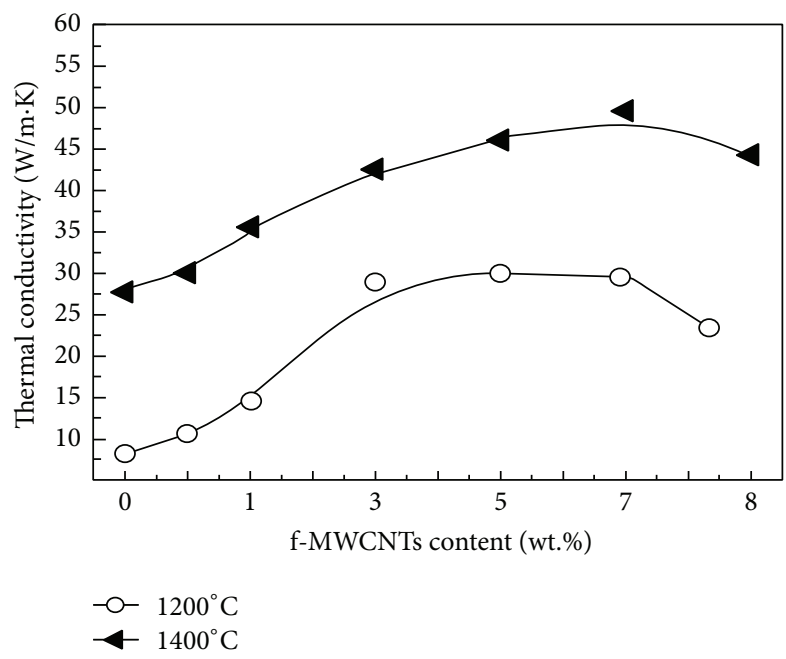

FIGURE 11: Thermal conductivity data of nanocomposites.

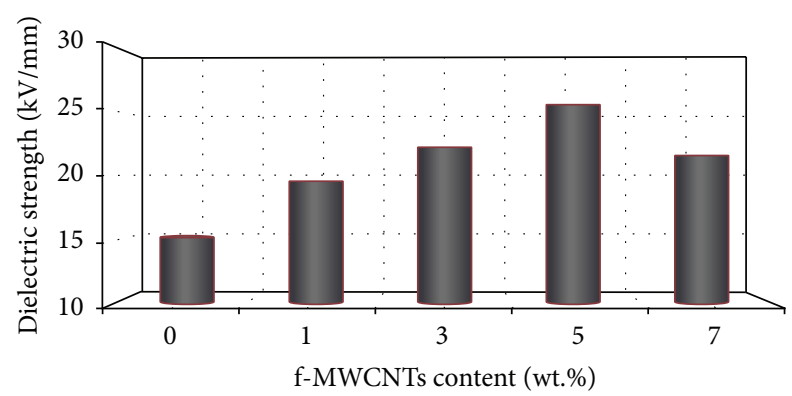

FIGURE 12: Effect of f-MWCNTs on dielectric strength of nanocomposites.

applications. The change in weight of the nanocomposites due to various solvent exposure (Figure 16) suggested their minimum susceptibility to the solvents compared to the pure blend (VER/EP) indicating highly cross-linked systems. The solvent ingress reduced with the increased f-MWCNTs loading and reached a minimum at $5 \mathrm{wt}$.\% due to the efficient matrix/f-MWCNTs adhesion caused by hydrogen bonding

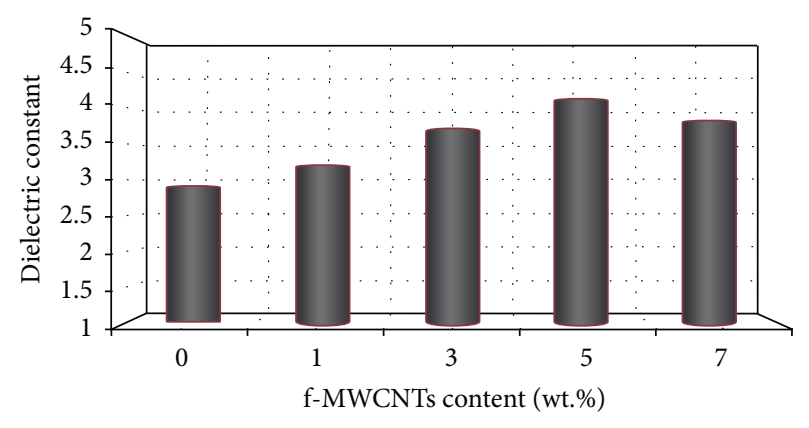

FIGURE 13: Effect of f-MWCNTs on dielectric constant nanocomposites at $1 \mathrm{MHz}$.

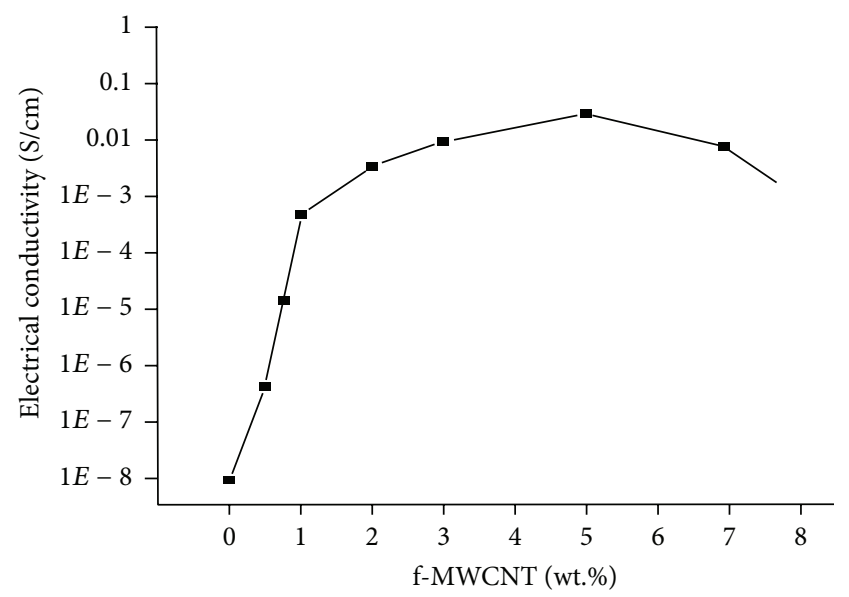

FIGURE 14: Electrical conductivity of nanocomposites.

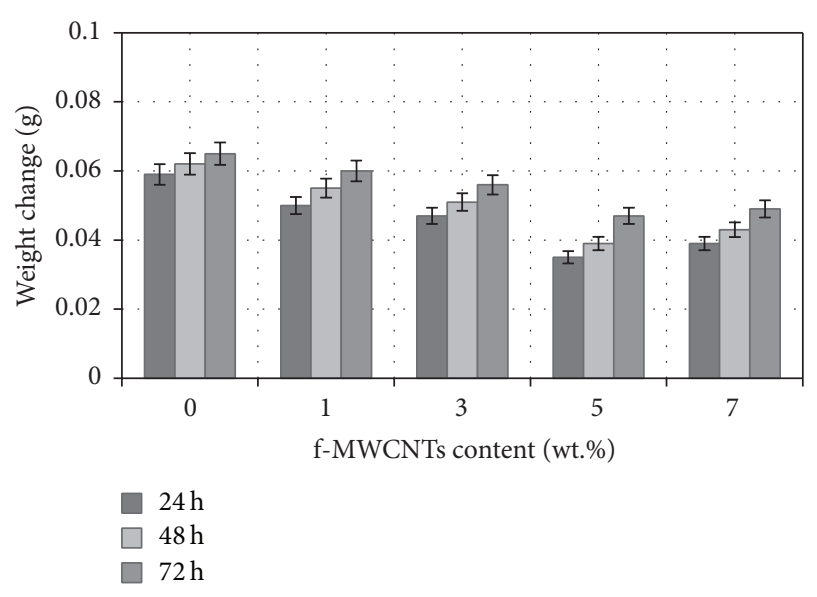

Figure 15: Effect of f-MWCNTs on corrosive properties of nanocomposites.

between the two. At 7 wt.\%, the clustering of nanofiller results in cracks and micro voids on the nanocomposite surface, increasing the solvent uptake causing interfacial debonding between the matrix and filler particles [16]. This is also the reason for the decrease in mechanical properties of nanocomposites at higher filler content. Thus, the above nanocomposites can exhibit better durability even when used for solvent based applications. 


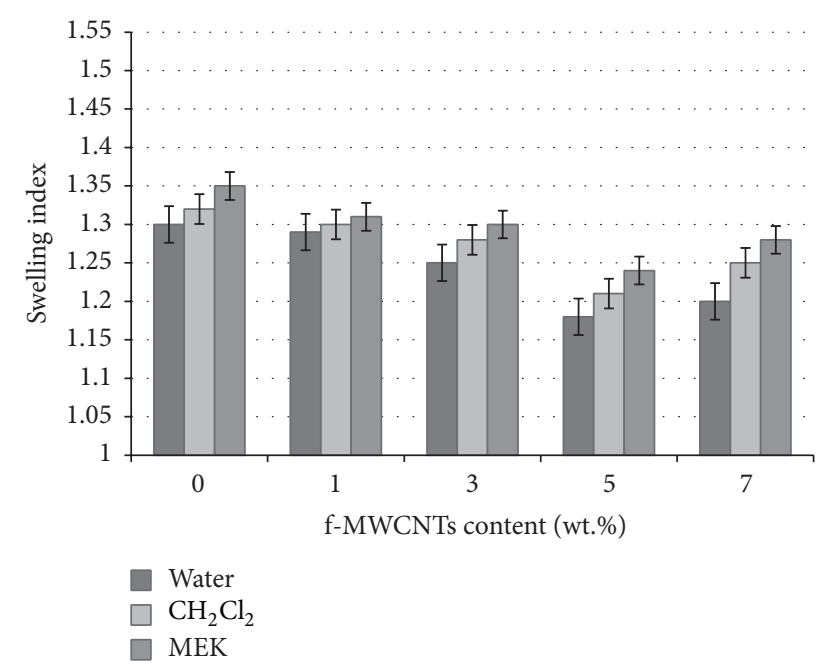

FIGURE 16: Effect of f-MWCNTs on swelling properties of nanocomposites.

\section{Conclusion}

The novelty of this work involves the incorporation of amine functionalized MWCNTs as reinforcement/nanofiller in varying proportions into Vinylester/epoxy blend matrix based nanocomposites which has never been designed before. Besides the fabrication, this study also reports the trend in mechanical, thermal, electrical, corrosive, and swelling properties of the nanocomposites with varying nanofiller content. The studies revealed enhancement in all the above properties of the nanocomposites mainly at low nanotube content, that is, $5 \mathrm{wt} . \%$, because, at higher concentrations (7 wt.\%), large amount of agglomerations is observed that act as stress concentrators and reduce the overall properties of nanocomposites. Thus, the above nanocomposites with optimum fMWCNTs content could serve for a variety of structural, thermal, electrical, and solvent based applications.

\section{Conflict of Interests}

The authors declare that there is no conflict of interests regarding the publication of this paper.

\section{Acknowledgments}

The authors of this paper are thankful to KIIT University for their support and help. The assistance provided by IIT, Kharagpur, during the characterization of some of the experimental work is greatly acknowledged.

\section{References}

[1] C. Harrats, S. Thomas, and G. Groeninckx, Micro- and Nanostructured Multiphase Polymer Blend Systems: Phase Morphology and Interfaces, CRC Press, 2005.

[2] Handbook of Polymer Blends and Composites, vol. 1, iSmithers Rapra Publishing, 2002.
[3] P. Harishankar, Y. V. Mohana Reddy, and K. Hemachandra Reddy, "Polymer blended (epoxy/vinylester) nanocomposites resistance against pulling \& sliding wear loads," International Letters of Chemistry, Physics and Astronomy, vol. 18, pp. 75-90, 2014.

[4] A. P. Praharaj, D. Behera, T. K. Bastia, and A. K. Rout, "Hybrid composite laminates from ESOA-BisGMA blend and 2-hydroxyethyl acrylate (HEA) treated jute fiber," American Journal of Polymer Science \& Engineering, vol. 3, no. 1, pp. 1-12, 2015.

[5] B. Wetzel, F. Haupert, and M. Q. Zhang, "Epoxy nanocomposites with high mechanical and tribological performance," Composites Science and Technology, vol. 63, no. 14, pp. 2055-2067, 2003.

[6] G. Peng, L. Gao, Z. Zhan, H. Wang, and W. Hao, "Wear behavior of $\mathrm{Al}(\mathrm{OH})_{3}-\mathrm{GF} /$ epoxy composites in low velocity," Polymer Bulletin, vol. 63, no. 6, pp. 911-919, 2009.

[7] G. Suresha, M. Chandra, P. R. S. Rao, P. Sampathkumarau, S. Seetharumu, and V. Vartha, "Friction and wear characteristics of carbon-epoxy and glass-epoxy woven roving fiber composite," Indian Journal of Engineering \& Materials Sciences, vol. 13, pp. 535-541, 2006.

[8] D. Lingaraju, K. Ramji, M. P. Devi, and U. R. Lakshmi, "Mechanical and tribological studies of polymer hybrid nanocomposites with nano reinforcements," Bulletin of Materials Science, vol. 34, no. 4, pp. 705-712, 2011.

[9] J. Shen, W. Huang, L. Wu, Y. Hu, and M. Ye, “The reinforcement role of different amino-functionalized multi-walled carbon nanotubes in epoxy nanocomposites," Composites Science and Technology, vol. 67, no. 15-16, pp. 3041-3050, 2007.

[10] D. Behera, H. Satapathy, and A. K. Banthia, "Synthesis, purification and curing studies of vinyl ester network," Pigment and Resin Technology, vol. 36, no. 5, pp. 271-278, 2007.

[11] R. F. Landel and L. E. Lielsen, "\% Particulate-filled polymers," in Mechanical Properties of Polymers and Composites, chapter 7, p. 377, 2nd edition, 2010.

[12] A. Peigney, C. Laurent, E. Flahaut, R. R. Bacsa, and A. Rousset, "Specific surface area of carbon nanotubes and bundles of carbon nanotubes," Carbon, vol. 39, no. 4, pp. 507-514, 2001.

[13] J. Y. Shin, H. D. Park, K. J. Choi, K. W. Lee, J. Y. Lee, and J. W. Hong, "Electrical properties of the epoxy nanocomposites according to additive," Transactions on Electrical and Electronic Materials, vol. 10, pp. 97-101, 2009.

[14] Z. Wang, J. K. Nelson, H. Hillborg, S. Zhao, and L. S. Schadler, "Dielectric constant and breakdown strength of polymer composites with high aspect ratio fillers studied by finite element models," Composites Science and Technology, vol. 76, pp. 29-36, 2013.

[15] H. P. S. Abdul Khalil, M. Jawaid, and A. Abu Bakar, "Woven hybrid composites: water absorption and thickness swelling behaviours," BioResources, vol. 6, no. 2, pp. 1043-1052, 2011.

[16] T. T. Law and Z. A. M. Ishak, "Water absorption and dimensional stability of short kenaf fiber-filled polypropylene composites treated with maleated polypropylene," Journal of Applied Polymer Science, vol. 120, no. 1, pp. 563-572, 2011. 

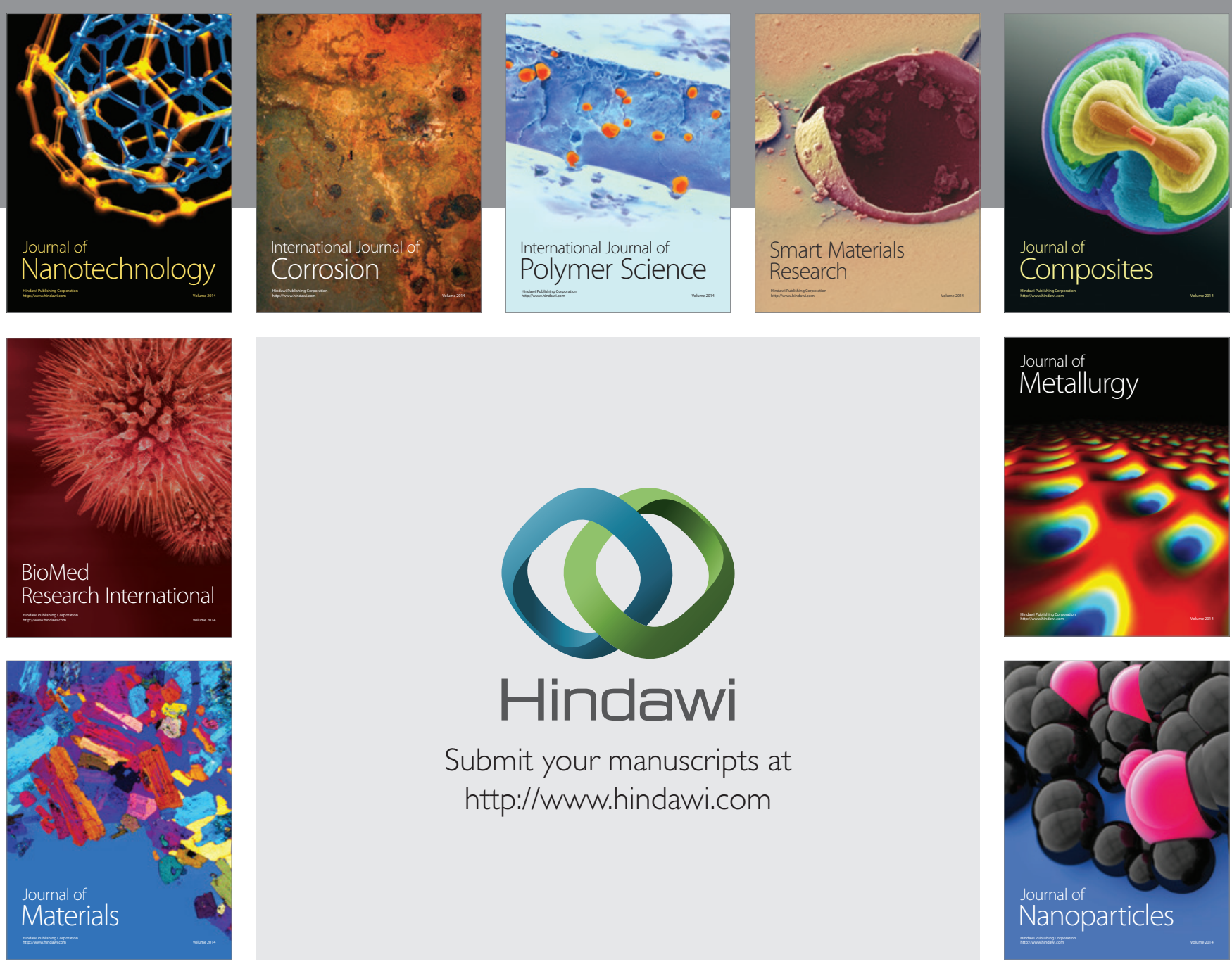

Submit your manuscripts at http://www.hindawi.com
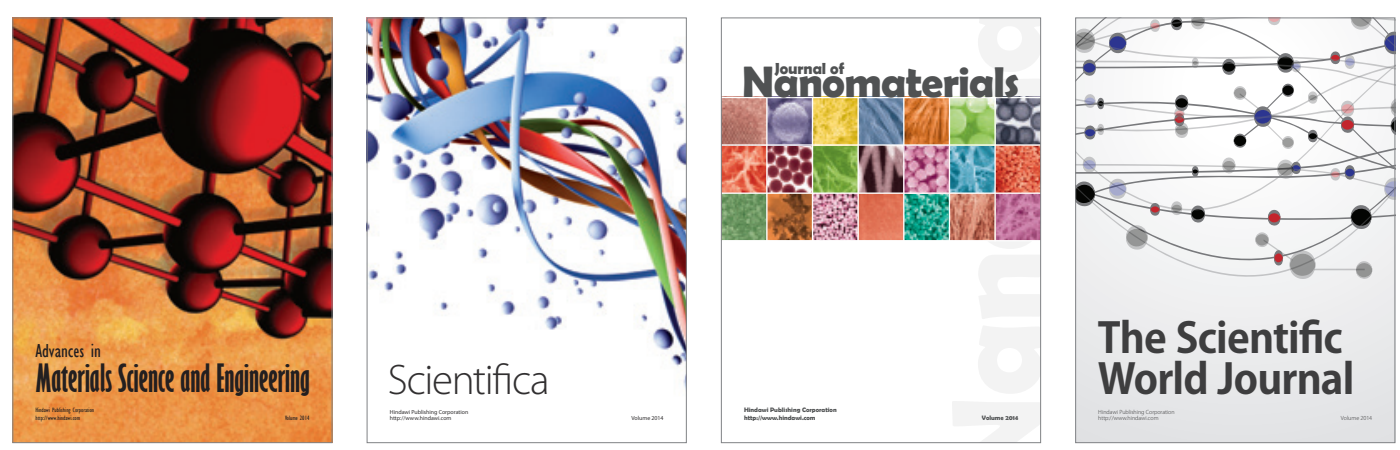

\section{The Scientific World Journal}
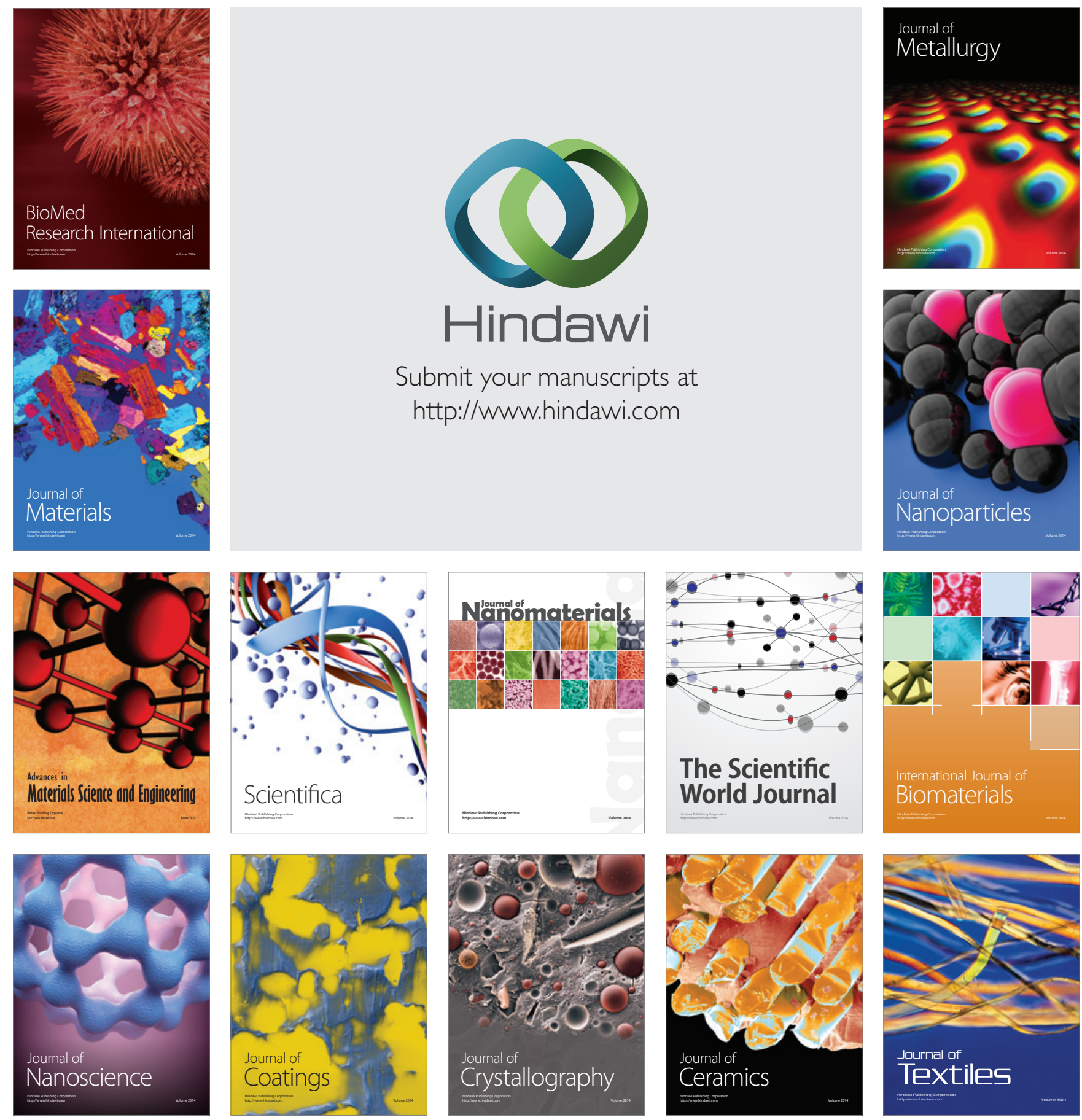